\title{
ANALISIS SWOT KEBUTUHAN KARYAWAN PERBANKAN SYARIAH DARI SARJANA EKONOMI SYARIAH IAIN PALANGKA RAYA
}

\author{
Jelita dan Wilmar Okto Wardana \\ IAIN Palangka Raya
}

\begin{abstract}
This research background in IAIN Palangka Raya as one of the colleges that there is a container for printing human resources and potentional knowledgeable in the world of work. One of the graduate printed is a graduate of the Faculty of Economics and Business Islam with competence in the Islamic finance. But the facts on the ground are not little public data show that graduates become more dominant than the employees in Islamic banking scholars who really has the educational background of Islamic economics. The problem begins with the researcher tried to explore data about the SWOT analysis of the needs of potential economic scholars of sharia in Islamic banking city of Palangka Raya. The problem in this research are 1) Strength, 2) weakness, 3) opportunities, 4) the threats facing prospective Bachelor of Islamic Economics IAIN Palangka Raya on Islamic Banking city of Palangka Raya and 5) How can the application of a SWOT analysis in developing prospective Bachelor of Islamic Economics IAIN Palangka Raya Britain on Islamic Banking city of Palangka Raya.

This study used qualitative research methods, the research subject is the faculty of economics and business of Islamic banking Islamic and 4 cities Palangka Raya ie BMI, BSM, BRIS and BPR Mitra Amanah. Data collection techniques through, observation, interviews and documentation; validating data through triangulation techniques, then the data analyzed by data reduction, a data display and conclusion verification.

The results of this study are 1) The strength of a. have a basic knowledge of Islamic banking b. have a scholarly foundation related to Islamic financial institutions c. Output Islamic scholars who are experts in Islamic economics. 2) The weakness in terms of academic, SDM Teachers, curriculum learning, relationship. While the non-academic terms that mindset is still low degree candidate. 3) Opportunities have added value, priority religion, knowledge about Islamic banking contract-agreement, an understanding of the products; have communication skills and proficiency in a polite and courteous and knowledge in the field of Islamic religion. 4) Threats to the economy in the banking degree candidate is not looking at the educational background, dressed and physical conditions prescribed for frontline staff. 5) The results of a SWOT analysis required by prospective students of Islamic Economics Iain Palangka Raya on Islamic banking: a. Internal 1) Improving the teaching of human resources. 2) Development of the learning curriculum. 3) improve the relationship in the field of education. 4) Provide training in human resource development sharia economics degree candidate b. External Improving student mindset to be able to develop themselves independent, creative, innovative and high work ethic.
\end{abstract}

Keywords : SWOT Analysis, scholars of Islamic economics

\section{PENDAHULUAN}

\section{Latar Belakang}

Fakultas Ekonomi dan bisnis Islam IAIN Palangka Raya sebagai salah satu perguruan tinggi yang satu-satunya di provinsi Kalimantan Tengah pencetak sumber daya manusia yang 
berpengetahuan dan potensional di bidang keuangan syariah. Namun, fakta di lapangan tidak sedikit data menunjukkan bahwa lulusan umum lebih dominan menjadi karyawan di perbankan syariah dibandingkan sarjana yang benar memiliki latar belakang pendidikan ekonomi syariah. Oleh karena itu, perlu dilakukan sebuah analisis agar hal tersebut dapat tercapai salah satunya dengan menggunakan analis SWOT.

Diketahui bahwa output lulusan sarjana ekonomi syariah di tahun 2013 sampai dengan 2016 sebanyak 93 orang, lulusan sarjana ekonomi syariah terdapat 8 orang yang bekerja di perbankan. Pada grafik ini menunjukkan bahwa fakta di lapangan sangatlah mengejutkan di tahun 2017 pada lulusan tahun 2013 dan 2015 Fakultas Ekonomi dan Bisnis Islam tidak ada lagi yang menjadi karyawan perbankan syariah, sedangkan pada lulusan tahun 2014 dan 2016 hanya tiga orang yang menjadi karyawan di perbankan syariah, yaitu saudari N, NR, HM dan yang menjadi karyawan bank konvensional yaitu EFR, DI, NAD, AN dan M serta lulusan IAIN Palangka Raya bukan dari prodi Ekonomi Syariah yang bekerja di perbankan syariah ialah saudara A, T, MFA dan saudari SA, AN, selebihnya bekerja sebagai pegawai negeri sipil, dosen, maupun karyawan di instansi perseroan terbatas (PT), swasta dan pengusaha bahkan masih ada yang belum mendapatkan pekerjaan atau berhenti dari pekerjaan sebelumnya. ${ }^{1}$

Beranjak dari penjelasan di atas, ada beberapa hal yang menurut penulis perlu di pertanyakan. Bagaimana kekuatan, kelemahan, peluang dan ancaman sarjana ekonomi syariah IAIN Palangka Raya? Bagaimana strategi untuk mengembangkan sarjana ekonomi syariah dengan menggunakan analisis SWOT?

\section{Kajian Teori}

Analisis "SWOT" merupakan akronim untuk kata-kata"strength" (kekuatan), "weaknesses" (kelemahan), "opportunities" (peluang) dan "threats" (ancaman). Faktor kekuatan dan kelemahan terdapat dalam tubuh suatu organisasi, termasuk satuan bisnis tertentu sedangkan peluang dan ancaman merupakan faktor-faktor lingkungan yang dihadapi oleh organisasi atau perusahaan atau satuan yang bersangkutan.

Ekonomi syariah adalah suatu cabang ilmu yang mempelajari cara hidup, pola hidup dengan menggunakan prinsip syariah yang berdasarkan pada Al-Qur'an dan Hadits agar mendapatkan manfaat di dunia dan di akhirat.

Bank syariah adalah bank yang beroperasi sesuai dengan prinsip-prinsip Islam, yakni bank dengan tata cara dan operasinya mengikuti ketentuan-ketentuan syariah Islam salah satu unsur yang harus dijauhi dalam muamalah Islam adalah praktik-praktik yang mengundang unsur riba.

Bank syariah yang terdiri dari BUS, UUS, serta BPRS pada dasarnya melakukan kegiatan usaha yang sama dengan bank konvensional, yaitu melakukan penghimpunan dan penyaluran dana masyarakat di samping penyediaan jasa keuangan lainnya. Perbedaannya adalah seluruh kegiatan usaha bank syariah, UUS dan BPRS didasarkan pada prinsip syariah. Implikasinya, di samping harus selalu sesuai dengan prinsip hukum Islam, juga karena dalam prinsipnya syariah memiliki berbagai variasi akad yang lebih banyak akan dibandingkan menimbulkan variasi produk yang lebih produk bank konvensional. ${ }^{2}$

Setiap individu mempunyai kebutuhan-kebutuhan yang hendak dipenuhi. Dalam memenuhi kebutuhan-kebutuhan tersebut, setiap individu mempunyai sikap dan perilaku yang berbeda satu sama lain. Sebaliknya, apabila ada suatu kebutuhan yang tidak terpenuhi, juga akan berdampak pada perubahan sikap dan perilakunya. Ini menunjukkan bahwa kebutuhan mem-

\footnotetext{
1 Hasil observasi kepada para alumni 15 April 2017.

2 Ibid.,h. 72.
} 
punyai peranan yang sangat penting dan menentukan tingkah laku manusia.Tingkah laku manusia tersebut mengarah pada pencapaian tujuan yang dapat memenuhi atau memuaskan kebutuhan itu, begitu pula seharusnya, sehingga terjadi suatu lingkaran motivasi yang tidak pernah putus.

Kebutuhan (need) adalah: "a natural requirement white should be satisfied in order to secure a better organic capability" sedangkan Chaplin (2002), mendefinisikan need (kebutuhan) sebagai (1) satu substansi seluler yang harus dimiliki oleh organisme, agar organisme tersebut tetap sehat; (2) lebih umum, segala kekurangan, ketiadaan, atau ketidakpuasan yang dirasakan seseorang, sehingga, merusak kesejahteraannya.

Kebutuhan merupakan suatu keperluan yang harus dipenuhi untuk mencapai organisme, Kebutuhan muncul ketika seorang kesejahteraan merasa kekurangan, ketidak sempurnaan yang dapat merusak kesejahteraannya. Dengan kata lain, kebutuhan muncul karena adanya ketidakseimbangan dalam diri individu sehingga membuat individu bersangkutan membuat suatu tindakan, tindakan itu mengarah pada suatu tujuan, dan tujuan tersebut diharapkan dapat memenuhi kebutuhan yang ada. ${ }^{3}$

Keseluruhan teori motivasi yang di kembangkan oleh Maslow berintikan pendapat yang mengatakan bahwa kebutuhan manusia itu dapat diklasifiksikan pada lima hirarki kebutuhan yaitu; kebutuhan fisiologi, akan keamanan, sosial, esteem dan kebutuhan untuk aktualisasi diri.

\begin{tabular}{|l|l|}
\hline Komponen & Substansi komponen \\
\hline Physiological (fisik) & Hunger (lapar), thirst (haus), bodily comforts (kenyamanan tubuh) \\
\hline Safety / security (keamanan) & Out of danger (tidak ada dalam kondisi bahaya) \\
\hline $\begin{array}{l}\text { Belongingness and love (rasa } \\
\text { memiliki dan cinta) }\end{array}$ & $\begin{array}{l}\text { Affiliate with others (berhubungan dengan orang lain), be accepted } \\
\text { (merasa diterima orang lain) }\end{array}$ \\
\hline Esteem (penghargaan) & $\begin{array}{l}\text { To achieves (berprestasi), be competent (kompeten / ahli), gain } \\
\text { approval and recognition (mendapatkan persetujuan dan } \\
\text { pengakuan) }\end{array}$ \\
\hline Cognitive (kognisi) & $\begin{array}{l}\text { To know (mengetahui), to understand (memahami), explore } \\
\text { (menjelajah) }\end{array}$ \\
\hline Aesthetic (keindahan) & Symmetry (simetri), order (ketertiban), and beauty (keindahan) \\
\hline $\begin{array}{l}\text { Self-actualization (aktualisasi } \\
\text { diri) }\end{array}$ & $\begin{array}{l}\text { To find self-fulfillment (pemenuhan keinginan diri), and realize } \\
\text { one's potential (realisasipotensi diri) }\end{array}$ \\
\hline $\begin{array}{l}\text { Self-transcendence } \\
\text { (trensendensi diri) }\end{array}$ & $\begin{array}{l}\text { To connect to something beyond the ego or to help pther find self- } \\
\text { fulfillment and realize their potential (untuk terhubung ke sesuatu } \\
\text { yang di luar ego atau membantu orang lain menemukan } \\
\text { pemenuhan diri dan menyadari potensi mereka) }\end{array}$ \\
\hline
\end{tabular}

Sumber daya Ekonomi Syariah secara umum mempunyai pengetahuan di bidang syariah seperti memahami ekonomi syariah itu sendiri baik dari konsep, hukum dan penerapan serta memiliki kemampuan berkomunikasi dengan baik sehingga mampu menyampaikan atau menerapkan bagaimana konsep dan hukum ekonomi syariah di masyarakat. Tidak hanya memiliki pengetahuan di dibidang Ekonomi Syariah, Sumber daya ekonomi syariah haruslah mempunyai sifat tanggung jawab, jujur, cakap dan cerdas. ${ }^{4}$

${ }^{3}$ Desmita, Psikologi Perkembangan Peserta Didik, Bandung, 2011 h. 59-60

4Ibid., h. 16

Analisis SWOT Kebutuhan Karyawan Perbankan Syariah dari Sarjana Ekonomi Syariah IAIN Palangka Raya 


\section{METODE}

\section{Lokasi dan waktu penelitian}

Penelitian ini akan di laksanakan di Fakultas Ekonomi dan Bisnis Islam IAIN Palangka Raya dan perbankan syariah Kota Palangka Raya. Waktu penelitian dilakukan selama dua bulan, satu bulan pertmana (oktober) mengumpulkan data dan bulan kedua (november) menganalisis data

\section{Subje dan Objek Penelitian}

Subjek dari pihak perbankan syariah berjumlah 4 (empat) orang masing-masing perwakilan dari PT. BRI Syariah, Tbk Cabang Palangka Raya, PT. Bank Muammalat Indonesia Tbk, Cabang Palangka Raya, PT. Bank Syariah Mandiri, Tbk Cabang Palangka Raya dan PT. Bank Perkreditan Rakyat Syariah Mitra Amanah Cabang Palangka Raya serta beberapa orang lulusan yang berkerja di perbankan syariah Kota Palangka Raya. Informan penelitian ini pihak FEBI yang berjumlah 5 orang yang terdiri dari Wakil Dekan I FEBI, Wakil Dekan II FEBI, Wakil Dekan III FEBI, dan 2 (dua) orang Dosen FEBI.

Objek dalam penelitian ini adalah Analisis SWOT kebutuhan karyawan perbankan syariah dari sarjana Ekonomi Syariah Fakultas Ekonomi dan Bisnis Islam IAIN Palangka Raya.

\section{Teknik Pengumpulan Data}

Penelitian ini menggunakan teknik observasi, wawan dan dokumentasi dalam mengumpulkan data-data yang di perlukan dalam melakukan penelitian ini.

\section{Pengabsahan Data}

Untuk mengetahui tingkat pengabsahan data pada penelitian ini, peneliti menggunakan triangulasi data, triangulasi yang di gunakan merupakan triangulasi metode.

\section{HASIL DAN PEMBAHASAN}

Kekuatan yang dimiliki para sarjana ekonomi syariah yaitu seperti berikut.

1. Fakultas Ekonomi dan Bisnis Islam mengajarkan dan membentuk karakter sarjana ekonomi syariah dengan pengetahuan tentang akad-akad syariah yang disertai kemampuan untuk menjabarkannya melalui dalil-dalil al-Qur'an, sunnah, Ijma, dan Qiyas.

2. Fakultas Ekonomi dan Bisnis Islam memiliki landasan keilmuan perbankan, khususnya perbankan syariah yang diajarkan kepada sarjana ekonomi syariah agar mampu memahami perilaku organisasi, manajemen pemasaran dan berbagai landasan keilmuan yang berkaitan dengan lembaga keuangan syariah pada umum dan pada khususnya perbankan syariah.

3. Output sarjana ekonomi syariah di Fakultas Ekonomi dan Bisnis Islam IAIN Palangka Raya yaitu seorang muslim atau muslimah memiliki nilai religius tinggi dengan bekal keagamaan agar dapat menjalankan setiap pekerjaan kelak dengan sifat nabi shiddiq, amanah, fathonah, dan tabligh.

Kelemahan yang dimiliki oleh para sarjana ekonomi syariah yaitu (1) lemahnya soft skill yang di miliki oleh sarjana ekonomi syariah kurang siapnya dalam menghadapi dunia kerja di perbankan syariah; (2) pola pikir para sarjana masih rendah dalam bersaing; (3) rendahnya kesadaran sarjana untuk mengembangkan skill dengan mengikuti berbagai pelatihan; (4) kurang mengasah minat dan bakat mereka dengan terlibat langsung dalam pengelolaan kegiatan kampus, seperti kopma atau berbagai kegiatan yang mampu menerapkan ilmu yang didapat di ekonomi syariah; dan (5) kurang menjalin hubungan dengan internal perbankan syariah, baik 
dari segi alumni yang bekerja di perbankan syariah ataupun orang yang dikenal yang bekerja di perbankan syariah.

Peluang bagi sarjana ekonomi syariah yaitu seperti berikut.

1. Beragama Islam hal ini dinyatakan oleh 3 bank selain BRI Syariah.

2. Mengetahui tentang akad-akad perbankan syariah apalagi mampu memahami secara keseluruhan dari aspek dalil dan implikasinya dalam kegiatan muamalah.

3. Memahami produk-produk yang dijual oleh perbankan syariah kepada konsumen.

4. Memiliki skill dan kecakapan dalam komunikasi sopan dan santun.

5. Memiliki penampilan yang menarik dan bersih.

6. Memiliki integritas kerja yang tinggi

7. Taat beragama dan terampil mengaji al-Qur'an.

Ancaman bagi calon sarjana ekonomi syariah yaitu sebagai berikut.

1. Memiliki penampilan menarik bagi staf frontliner (CS dan Teller).

2. Rendahnya kemampuan SDM dibidang perbankan syariah yaitu calon sarjana atau sarjana kurang menguasai produk-produk perbankan syariah.

3. Manajemen SDM di perbankan syariah masih menganut pada pola manajemen perbankan konvensional sehingga ijazah dan keterampilan khusus yang dimiliki oleh calon sarjana ekonomi syariah bukanlah prioritas utama.

4. Pengalaman kerja.

Strategi analisis SWOT dalam mengembangkan sarjana ekonomi syariah IAIN Palangka Raya antara lain seperti berikut.

a. Faktor Internal

1) Meningkatkan kemampuan SDM pengajar di Fakultas Ekonomi dan Bisnis Islam Negeri.

2) Pengembangan kurikulum.

3) Meningkatkan relationship pihak IAIN dengan perbankan syariah.

b. Eksternal

Kebijakan dalam manajemen perbankan syariah memang berbeda-beda sebab itu strategi untuk mengatasi ancaman dan peluang dengan dimiliki oleh calon sarjana ekonomi syariah, yaitu menggali bakat dan minat bagi calon sarjana.

Data hasil yang peneliti kumpulkan bahwa rendahnya hasil rekrutmen di perbankan syariah beberapa tahun terakhir menjadi perhatian bahwa pola sarjana dan sarjana ekonomi syariah ini menurun. Oleh karena itu, perlu disadari untuk meningkatkan kualitas out put sarjana ekonomi syariah dalam bidang akademik dengan cara melakukan kerja sama dengan pihak perbankan untuk memperbaharui kurikulum perkuliahan, meningkatkan SDM pengajar, meningkatkan pengetahuan tentang akad-akad perbankan syariah apalagi mampu memahami secara keseluruhan dari aspek dalil dan implikasinya dalam kegiatan muamalah serta pengetahuan tentang produk-produk perbankan syariah serta dalam bidang non akademik dengan cara meningkatkan keterampilan, kemampuan dan kepercayaan diri dalam bekerja, berpenampilan menarik, memiliki skill dan kecakapan dalam komunikasi, memiliki integritas kerja yang tinggi dan pengalam kerja atau organisasi.

\section{PENUTUP}

Berdasarkan pengumpulan data terkait dengan analisis SWOT, kebutuhan calon sarjana ekonomi syariah IAIN Palangka Raya pada perbankan syariah Kota Palangka Raya, maka diketahui hasil berikut. 
1. Kekuatan calon sarjana ekonomi syariah yaitu memiliki pengetahuan dasar tentang perbankan syariah dan kemampuan menjabarkannya melalui dalil-dalil al-Quran, sunnah, Ijma dan Qiyas, 2) memiliki landasan keilmuan yang berkaitan dengan lembaga keuangan syariah pada umum dan pada khususnya perbankan syariah dan Output sarjana ekonomi syariah di Fakultas Ekonomi dan Bisnis Islam IAIN Palangka Raya, yaitu seorang muslim atau muslimah memiliki nilai religius tinggi dengan bekal keagamaan agar dapat menjalankan setiap pekerjaan kelak dengan sifat nabi shiddiq amanah fathonah dan tabligh.

2. Kelemahan ditinjau dari segi akademik yaitu rendahnya SDM pengajar di bidang perbankan, kurikulum pembelajaran ekonomi syariah belum berkembang sesuai dengan kebutuhan, dan kurangnya kerjasama pihak kampus dengan perbankan syariah di bidang pendidikan. Sedangkan segi non akademik yaitu pola fikir calon sarjana masih rendah dalam bersaing, mengembangkan soft skill dan mengaplikasi ilmu pengetahuan di koperasi atau bidang kewirausahaan lainnya.

3. Peluang yang dimiliki oleh calon sarjana ekonomi syariah memiliki nilai tambah, sebagian besar perbankan syariah memprioritaskan agama Islam, mengetahui knowledge tentang akad-akad perbankan syariah apalagi mampu memahami secara keseluruhan dari aspek dalil dan implikasinya dalam kegiatan muamalah, memahami produk-produk yang dijual oleh perbankan syariah kepada konsumen, memiliki skill dan kecakapan dalam komunikasi sopan dan santun, memiliki penampilan yang menarik dan bersih, memiliki integritas kerja yang tinggi taat beragama dan terampil mengaji al-Qur'an hal ini diungkapkan oleh 2 bank, yaitu BMI dan BSM.

4. Ancaman bagi calon sarjana ekonomi di perbankan yaitu pihak perbankan tidak memprioritaskan ijazah atau lulusan ekonomi syariah dalam rekrutmen tenaga kerja, untuk beberapa bidang jabatan di perbankan syariah ada beberapa ketentuan atau kebijakan tersendiri di pihak bank seperti mengutamakan penampilan dan postur tubuh untuk staf frontliner dan lulusan hukum untuk bidang legal (staf persiapan pemberkasan akad pembiayaan).

5. Hasil analisis SWOT yang dibutuhkan oleh calon mahasiswa Ekonomi Syariah IAIN Palangka Raya pada perbankan syariah yaitu:

a. Internal

1) Meningkatkan SDM / tenaga pengajar yang benar-benar memiliki pengetahuan luas tentang perbankan syariah.

2) Kurikulum pembelajaran harus ditingkatkan lagi, seperti mata kuliah yang berkaitan dengan akad-akad syariah disingkronkan dengan produk perbankan syariah.

3) Mengadakan kerjasama dengan lembaga perbankan syariah di bidang pendidikan, seperti merumuskan kurikulum pembelajaran yang sesuai dengan kebutuhan perbankan syariah, implementasi pelaksanaan PKL yang benar-benar terarah.

4) Mengadakan pelatihan atau pembekalan tentang rekrutmen karyawan atau kewirausahaan.

b. Eksternal

1) Meningkatkan pola pikir mahasiswa agar mampu mengembangkan diri yang mandiri, kreatif, inovatif dan etos kerja yang tinggi.

2) Meningkatkan kemampuan yang dibutuhkan oleh perbankan syariah seperti knowledge produk-produk perbankan syariah, kemampuan emosional, kemampuan komunikasi yang baik dan memahami struktur manajerial di perbankan syariah. 


\section{DAFTAR PUSTAKA}

Syarifuddin, Amir. 2001. Pengertian dan Sumber Hukum Islam. Jakarta: Bumi Aksara.

Hamid, M. Arifin. 2006. Membumikan Ekonomi Syariah di Indonesia. Jakarta.

M. Nastangin. 1997. Teori dan Praktek Ekonomi Islam. Yogyakarta: PT. Dana Bhakti Wakaf.

Sondang P. Siagian. 2009. Manajemen Strategik.Jakarta: PT Rineka Cipta.

Sondang P. Siagian. 2005. Teori Motivasi dan Aplikasinya. Jakarta: Rineka Cipta. 